\title{
La construcción de los espacios públicos de ocio en la ciudad de Quito
}

\section{Construction of public spaces for leisure at Quito city}

\author{
Edison Molina ${ }^{1}$, Patricia Ercolani², Guillermo Ángeles ${ }^{2}$ \\ ${ }^{1}$ Universidad Central del Ecuador. Facultad de Ciencias Agrícolas. Carrera de Turismo Ecológico. \\ Jerónimo Leiton y Av. La Gasca S/n. Ciudadela Universitaria. Quito. 170521. Ecuador \\ ${ }^{2}$ Universidad Nacional del Sur. Departamento de Geografía y Turismo. \\ Bahía Blanca, Buenos Aires, Argentina
}

\section{Resumen}

El desarrollo del artículo describe la construcción histórica de los espacios públicos de ocio en la zona urbana de la ciudad de Quito. Se realiza un recorrido por el pasado y se analiza la actualidad de los sitios dedicados al esparcimiento, recreación y actividades deportivas. Como resultado de este análisis se propone una clasificación con base en la realidad local y se identifican los principales lugares de disfrute dentro de las 32 parroquias urbanas elegidas para el presente estudio.

Palabras clave: espacios públicos, ocio, Quito, recreación, deportes.

\begin{abstract}
In this article, historic construction about public spaces for leisure at urban zone of Quito city is described. A walk by the past is made, and current situation of places dedicated for leisure, recreation and sport activities are analysed. As result, a classification based on the local reality is proposed, and main places for leisure are identified in the 32 urban parish selected in this study.
\end{abstract}

Keywords: public spaces, leisure, Quito, recreation, sports.

\section{Introducción}

La sociedad urbana de Quito ha tenido cambios importantes en las formas y la composición de la ciudad; razones fundamentales para analizar la actuación del ocio en la comunidad quiteña. El análisis del ocio desde el contexto geográfico permite comprender las dimensiones del espacio a través de las diferentes etapas que labraron el desarrollo de la urbanidad en la capital de los ecuatorianos.

Los orígenes de la composición poblacional se remontan a las organizaciones indígenas conocidas como los Quitus-Caras y luego Incas, que marcaron construcciones fortificadas en las cuales se concentraban los poderes, otorgando al área rural su am- plia acción de subsistencia que albergaba las zonas de cultivo. La llegada de la conquista española a la ciudad de Quito, el 6 de diciembre de 1534, significó una nueva concepción del urbanismo, frenando la evolución histórica de los primeros asentamientos e incorporando novedosos elementos en las nuevas estructuras que, necesariamente, determinaron la convivencia entre dos culturas diferentes que, con el pasar del tiempo, evolucionaron hacia una nueva y dinámica sociedad.

La influencia española instaurada en el territorio, en interacción con las costumbres y tradiciones, conformarían los pilares sobre los cuales se desarrollaron las construcciones de ocio para la sociedad instituida en Quito y, posteriormente, a partir de la 
conformación de la República, logró afianzarse otorgando un sentido de pertenencia. Fiestas, eventos, plazas, parques, teatros y demás expresiones representaron la forma de ocupar el tiempo de ocio.

En este estudio se realiza un análisis de la definición de los espacios públicos de ocio y, además, se realiza un recorrido por los principales lugares que estuvieron ligados a la recreación con gran significación para la población local en la instaurada ciudad de Quito.

\section{Materiales y métodos}

Para la construcción de la propuesta se tomaron en cuenta los enfoques cualitativo y cuantitativo. El enfoque cualitativo, por medio del estudio do- cumental, facilitó la definición del marco teórico sobre espacio público y ocio, a partir de lo cual fue posible obtener los datos más relevantes de la construcción histórica de los espacios públicos de ocio en la ciudad de Quito (Figura 1). El enfoque cuantitativo permitió desarrollar una clasificación en categorías y subcategorías de la actualidad de los espacios públicos de ocio con base en la realidad territorial de Quito. Tales espacios fueron identificados y geolocalizados para permitir su representación cartográfica por medio del sistema de información geográfica Arcgis 10.1@, y obtener una panorámica actual de la distribución de estos lugares en el territorio. Durante todo el proceso investigativo se realizó una amplia exploración de material bibliográfico, general y específico, obteniendo resultados muy relevantes para comprender la construcción de los espacios de ocio.

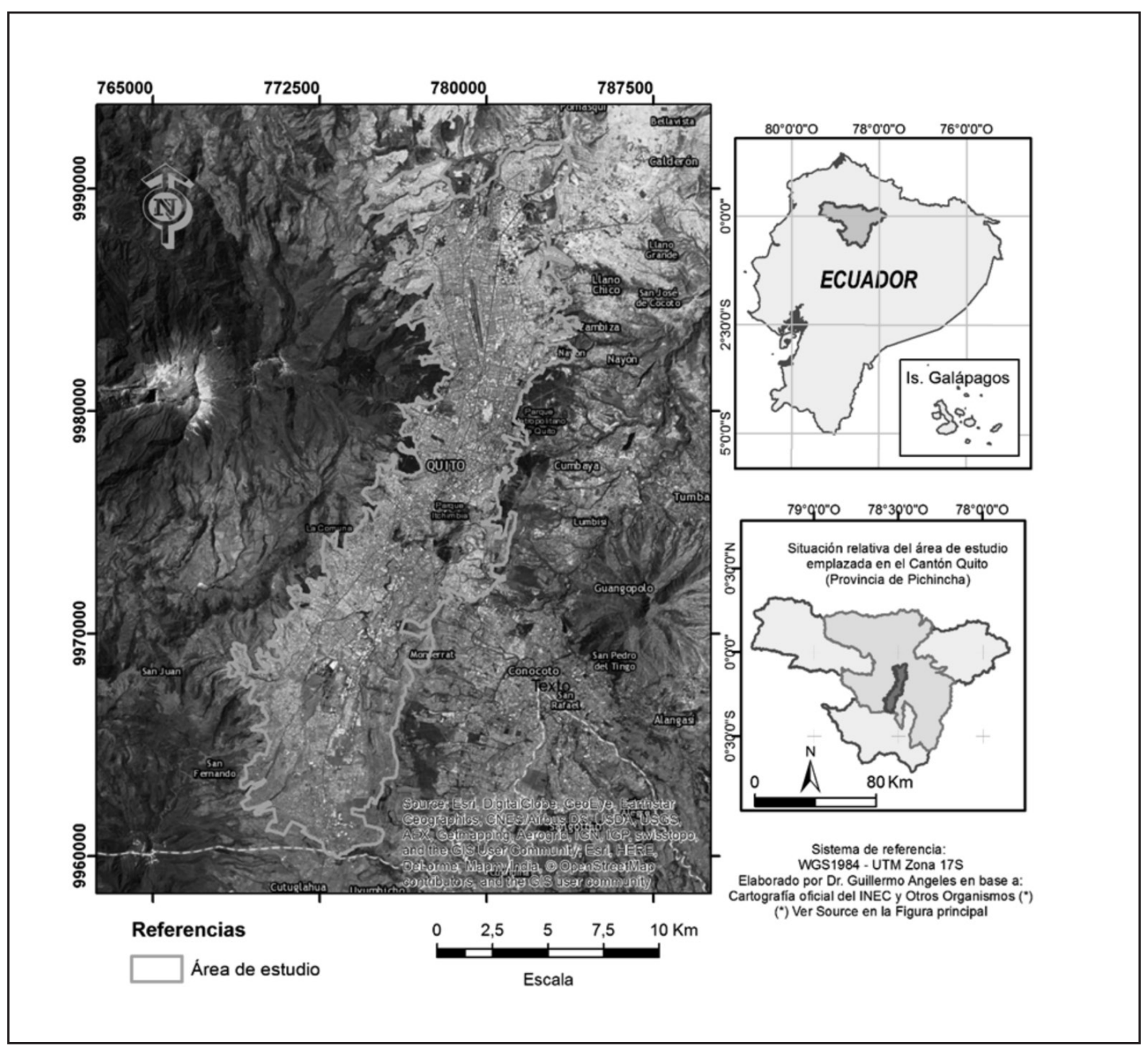

Figura 1. Localización del área de estudio. 


\section{Resultados y discusión}

\subsection{Hacia una conceptualización de los espacios público.}

Desde la perspectiva del urbanismo, un espacio público es de propiedad estatal y comprende a cualquier sitio abierto de libre acceso y circulación para los residentes y visitantes. Al respecto, Fleury (2007) señala que: "El espacio público es una expresión polisémica que designa un espacio a la vez metafórico y material. Como espacio metafórico, el espacio público es sinónimo de esfera pública o del debate público. Como espacio material, los espacios públicos corresponden tan pronto a espacios de encuentro e interacción sociales, como a espacios geográficos abiertos al público, o a una categoría de acción".

A su vez, la sociedad visualiza al espacio público como un lugar dinámico, lleno de actividades cotidianas, usos y conflictos; un espacio cargado de diferentes significados producto de la misma complejidad social de las ciudades, aún más en metrópolis históricas como Quito, donde se yuxtaponen fuertes identidades adquiridas a partir del proceso independentista y republicano del Ecuador. Al respecto Varela (1999) expresa que: “el espacio público es, radicalmente, un espacio para todos pero el significado espacial es, radicalmente, idiosincrásico de las personas y grupos que se relacionan con él. Y, obviamente, no todas las personas y grupos interpretan de igual forma el espacio urbano".

A nivel espacial, las diferentes políticas públicas se reflejan también en los espacios públicos y les otorgan una configuración cambiante a través de las acciones particularizadas que en ellos se desarrollan. Quito no es la excepción, y un claro ejemplo de ello son las ligas deportivas barriales, nacidas por la apropiación del espacio por parte de los deportistas aficionados, que les dieron identidad a estos lugares de recreación, y acompañan el crecimiento de la ciudad compartiendo los espacios verdes de la ciudad, administrados por el Municipio de Quito.

Los espacios públicos centrales están inmersos en los contextos políticos e históricos de un país. Las ciudades contienen a los espacios propicios creados por diferentes ritmos y demandas sociales y son consolidados a partir de diferentes visiones en relación a su gestión. A su vez, ésta se refleja en inversiones permanentes en pro de la conservación de estos espacios, a los cuales atribuyen ser el resultado de su planificación ante la sociedad, y ven en ellos los escenarios adecuados para gastar sus energías y replicarlas sobre otros espacios comunes alejados de los núcleos centrales. En este escenario existe una dualidad entre el accionar de lo público y lo privado, donde es posible observar brechas a favor de la participación de la inversión privada que avanza en la creación de nuevos espacios. Este desequilibrio se plasma en nuevos espacios para el consumo. Entre ellos, los grandes centros comerciales han producido cambios estructurales en las zonas urbanas y periféricas y en las prácticas de compras en la sociedad en sí. La sociedad por sus consumos amplía los tiempos de atención al cliente y convierte los espacios privados en espacios públicos, que también se ofrecen al disfrute del tiempo de ocio.

Para el caso de esta investigación se visualiza al espacio material como lo clasifica Fleury (2007), donde existe una relación con lo social y urbano que corresponde al enfoque de la geografía humanística. Asimismo, en el análisis se contemplan los espacios de ocio surgidos de la planificación pública y de aquellas iniciativas de las organizaciones sociales y sin fines de lucro existentes en la zona urbana de la ciudad de Quito.

\subsection{El ocio}

Varios autores han realizado sus investigaciones sobre esta temática. Entre ellos, Dumazedier (1971) define al ocio como "un conjunto de ocupaciones a las que el individuo puede entregarse de manera completamente voluntaria tras haberse liberado de sus obligaciones profesionales, familiares y sociales, para descansar, para divertirse, para desarrollar su información o su formación desinteresada, o para participar voluntariamente en la vida social de su comunidad".

En la definición expuesta por el sociólogo francés Joffre Dumazedier se explica claramente la intencionalidad para realizar actividades que produzcan liberación o placer independientemente de las tres funciones por él identificadas: el descanso, la diversión y el desarrollo de la personalidad. La Teoría de las $3 \mathrm{D}$ con sus tres funciones (descanso, diversión y 
desarrollo de la personalidad) son diversas formas de concebir al ocio, facilitan el estudio, la clasificación y precisan la funcionalidad de los espacios en el área de estudio elegida para la investigación.

La primera función: el descanso, alivia la fatiga, libera las tensiones del trabajo de forma tanto física como emocional y todas las complejidades que las relaciones laborales originan, desde los trayectos al trabajo; así como la convivencia con la producción y las relaciones laborales. La segunda función: la diversión, contribuye a terminar con el aburrimiento rompiendo por completo la cotidianidad, es muy necesario para llevar interacción social en diferentes lugares y circunstancias de las habituales. Por último, la tercera función: el desarrollo de la personalidad, que alude a una formación práctica y permite nuevas formas de integración con grupos sociales, a partir del desarrollo de aptitudes ganadas en la formación.

\subsection{Pasado del ocio en el espacio quiteño: los pri- meros tiempos}

A pesar de que Colonia fue una etapa marcada por la imposición de la cultura española sobre la indígena; existieron momentos para la recreación. Las corridas taurinas eran las fiestas populares de gran convocatoria que se realizaban todo el año y no dependían de una fecha en particular para su organización.

Según la entrevista realizada al cronista de la Ciudad, Alfonso Ortiz en los especiales del Diario El Comercio (2014), éste afirma que "las corridas de toros eran las primeras fiestas públicas que se celebraron en Quito. Al principio, estas fiestas fueron para demostrar el poder de la clase dominante a través de las maniobras de los caballos y de los caballeros. No todo el mundo tenía un caballo. Pero poco a poco, esa fiesta, que marcaba una diferencia entre la élite y el pueblo comenzó a diluirse. El pueblo se apropió de ella. La vida cotidiana era muy plana, muy uniforme. Nosotros, ahora, tenemos un abanico gigantesco de diversiones. Podemos subir a una montaña, ir a una piscina, al cine o ver una película en nuestra sala... La fiesta, a partir de los años de la Colonia, era una válvula de escape. Cuando Atahualpa llegó a Cajamarca, al encuentro con Francisco Pizarro, llegaron músicos y gente cantando y bailando con la comitiva del Inca. Cada cosecha despertaba una fiesta. El espíritu festivo de los indígenas coincidió con el de los españoles".

La manera tradicional de divertirse en los tiempos de la Colonia se mantendría en la República, además de conservar el estilo de vida, las costumbres y las tradiciones en la ciudad. "Durante los primeros tiempos de la República, la ciudad seguirá manteniendo la misma ordenación y la misma conformación de los tiempos de la Colonia. $\mathrm{Su}$ aspecto físico no va a variar fundamentalmente $\mathrm{y}$, ni siquiera, van hacer su incursión los principios arquitectónicos que se planteaban en Europa" (Ulloa \& Darquea, 1983).

A finales del siglo XIX, se promueven los primeros cambios transcendentales del diseño urbano en Quito. Un acontecimiento claro de reconocer fue la transformación con estilo francés de la principal plaza de la ciudad, la Plaza Grande, más conocida como de La Independencia. Otro hito destacado fue la construcción del Teatro Sucre en el año 1886, de estilo neoclásico, que constituye uno de los escenarios de ópera más antiguos de Sudamérica.

"La ciudad empieza a mostrar una forma longitudinal con una zonificación que le caracterizará en el futuro. El norte será destinado a un uso residencial de la clase pudiente como muestra la implantación del paseo de La Alameda y el sur quedará para las clases desposeídas, donde comenzará ya el asentamiento de una incipiente industria, bodegas y galpones, en el más completo desorden" (Achig, 1983).

El primer parque instaurado en la ciudad de Quito es el parque de La Alameda, que pasó por un proceso de cambios (Figura 2). Inició en el siglo XVIII, con la construcción de monumentos y caminos alrededor de las lagunas; luego, en la época republicana, se edificó el primer observatorio astronómico de Sudamérica. En este período, el parque también sirvió como zona de pastoreo. En 1877, se realizó una reestructuración integral del parque, que lo convirtió en un paseo para la sociedad de élite de Quito; además, se instauró el primer jardín botánico que luego sería la escuela de Bellas Artes, lamentablemente, a finales del siglo XIX , como consecuencia de un gran incendio el edificio sería demolido. 


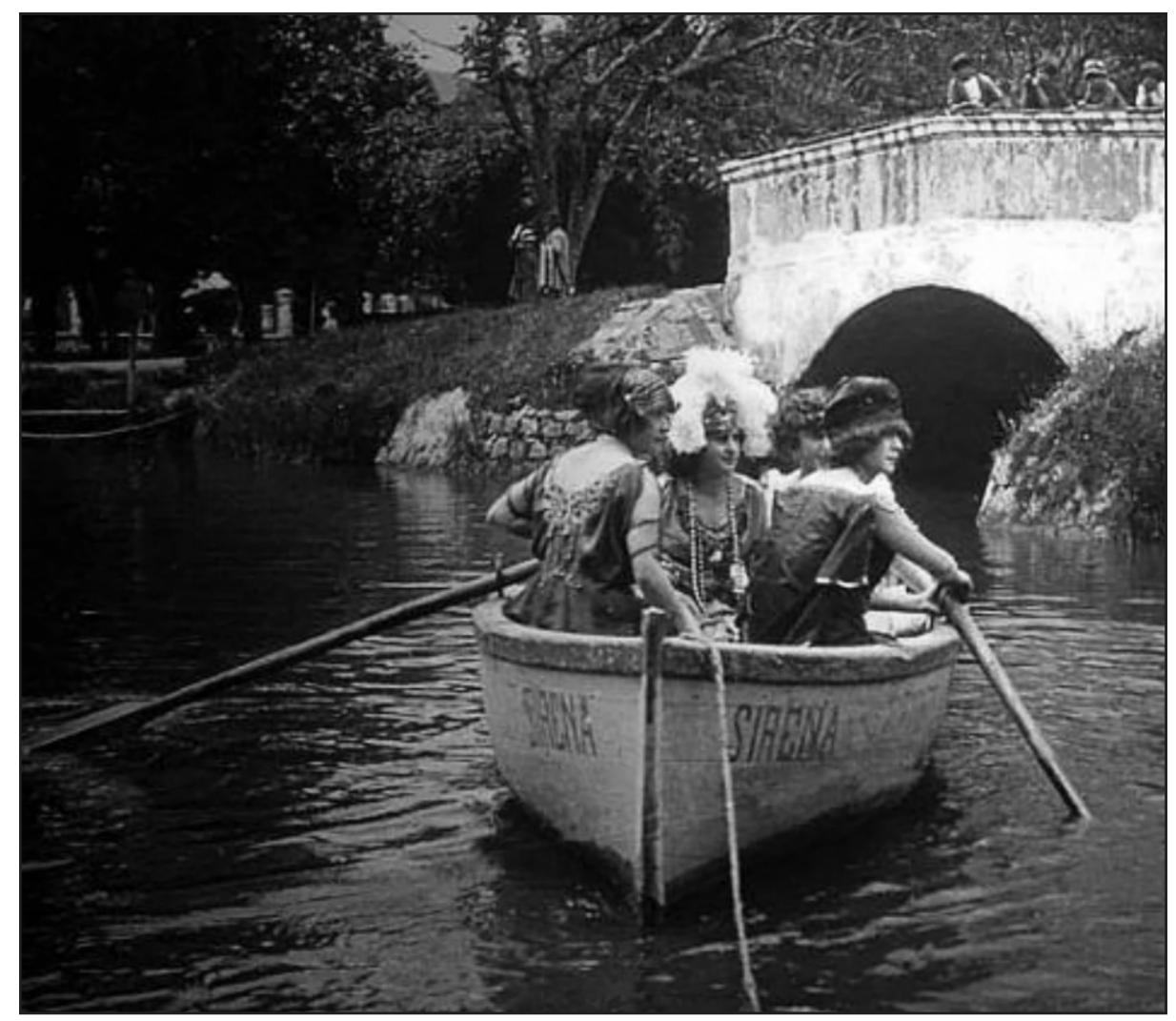

Figura 2. Parque La Alameda a comienzos del siglo XX. Fuente: Quito Nostálgico.

A inicios del siglo XX se identifica a Quito como una ciudad de crecimiento longitudinal, dejando a un lado al desarrollo central concéntrico, más aún con la llegada del ferrocarril en 1908, que facilitó el arribo del material pesado fundamental para las construcciones públicas. Las importaciones que realizaba el país en esa época ingresaban por el puerto de Guayaquil.

"Los hermanos César y Carlos Mantilla Jácome se propusieron desarrollar varios negocios en la pequeña, en aquel entonces, ciudad de Quito. Entre sus proyectos contaron: una agencia de carruajes, el primer hipódromo de la ciudad, la imprenta El Comercio (que más tarde se convertiría en el diario del mismo nombre) y la Empresa de Teatros y Hoteles de Quito. La Empresa de Teatros y Hoteles de Quito C.A. se fundó en 1945. Comprendió una cadena de varios teatros cinematógrafos y hoteles. Los inmuebles dentro de la ciudad de Quito fueron: el Teatro México, Teatro Cumandá, Teatro Puerta del Sol, Teatro Bolívar (Figura 3), Teatro Variedades, Teatro Central, Teatro Alameda, Teatro Colón, Hotel Colonial, Hotel Crillón,
Hotel Royal y Hotel Columbus” (Fundación Teatro Bolívar, Historia, 2010).

El cine mudo también comenzó a ser presentado para el entretenimiento de los quiteños, el teatro Variedades fue el escenario elegido, fundado en el año 1914. Posteriormente, los hermanos Mantilla también crearon su empresa de cines destacándose los cines Popular y 24 de mayo; además, aparecerán nuevos promotores que comenzarán la apertura de locales dedicados a brindar diversión cinematográfica.

Es importante señalar que la ciudad de Quito se asienta en el cruce del río Machángara, cuyas aguas, a principios del siglo XX, eran limpias y concentraba a la población para la realización de diferentes actividades, en especial lavar la ropa y tomar baños en sus alrededores. Los quiteños preferían ir los fines de semana en su tiempo libre a los balnearios disponibles en esa época con finalidades de ocio. Los principales balnearios eran los Pogyos, los Milagros, el Sena, la piscina de Lourdes y los baños del Yavirac, actualmente desaparecidos. 


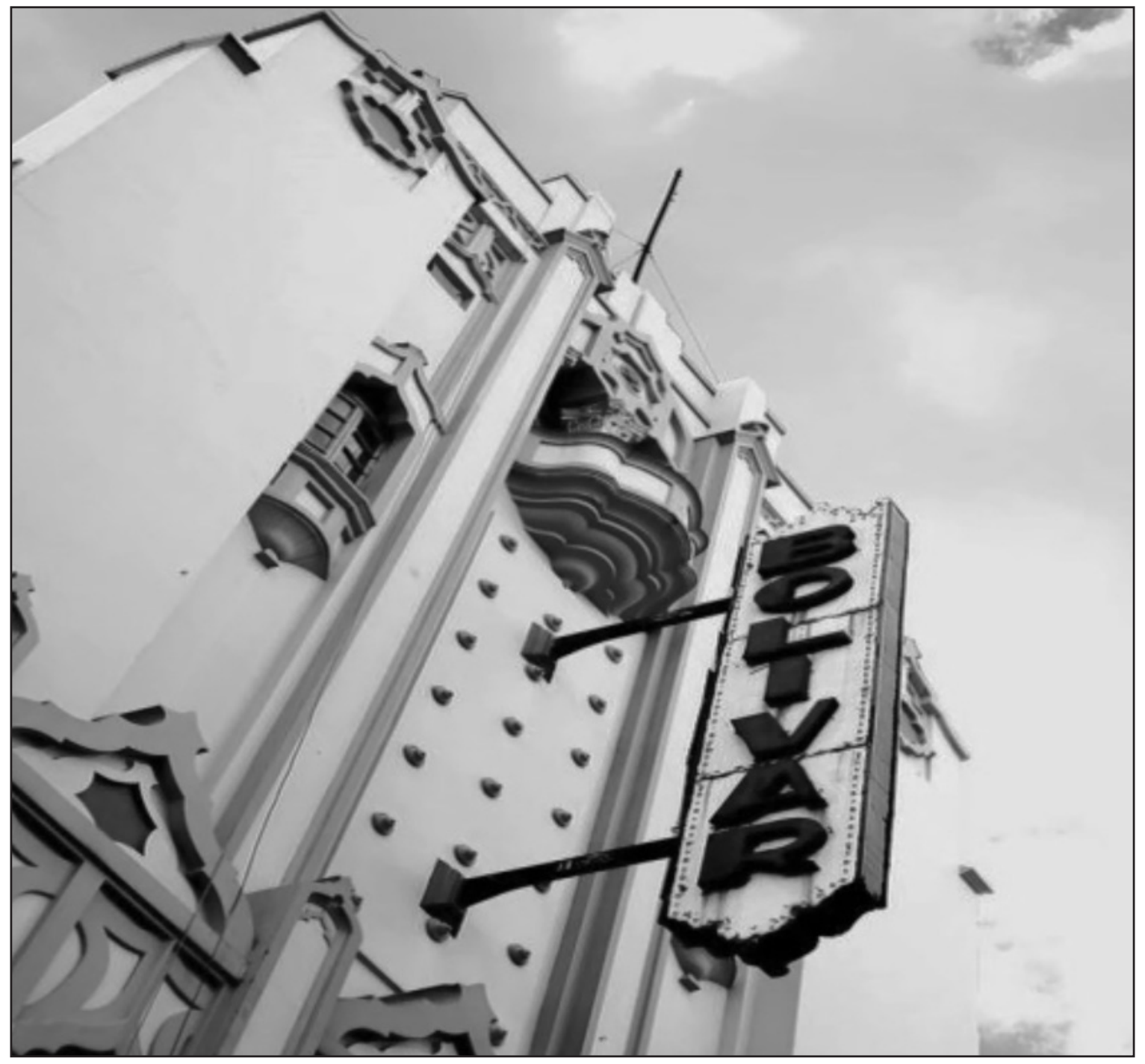

Figura 3. Fachada del Teatro Bolívar. Fuente: Quito Nostálgico.

En esos tiempos, los quiteños se bañaban en el desaparecido balneario "Los Pogyos", localizado en el lado noroccidental de la urbanización Tola Alta, al lado del que es ahora relleno del Machángara, prolongación de la plazoleta del $\mathrm{Cu}-$ mandá. Los "Pogyos" eran balnearios tradicionales de las familias capitalinas, que afirmaban que sus aguas frías y cristalinas eran medicinales... al sitio concurrían, en especial los fines de semana, por descanso y recreación. 'Los quiteños disfrutaron de numerosos sitios para bañarse. Antes de que llegara el agua potable a sus hogares. Así la piscina de Lourdes, que quedaba en el mesón de la Maldonado, entre las calles Borrero y Portilla; los balnearios de los Milagros, ubicados en la prolongación actual de la calle Sucre; los baños del
Yavirac, en la calle Ambato; El Sena al lado oriental del puente sobre el Machángara. En la calle Maldonado, etc. "La mayoría de estos baños han desaparecido..." (Carrión et al., 1997).

Las fiestas taurinas perduraban en la memoria del pueblo. Se erigieron las dos principales arenas taurinas en la ciudad: la Plaza Belmonte y la Plaza de Toros de Quito (Figura 4). La primera, inaugurada en el barrio tradicional de La Tola en el centro de la urbe en el año 1920. El lugar, desde sus inicios, tuvo varios propósitos; el principal fue la fiesta brava, además de múltiples representaciones artísticas que hasta la fecha continúan realizándose bajo la dirección de la compañía Triana, concesionaria del predio. 


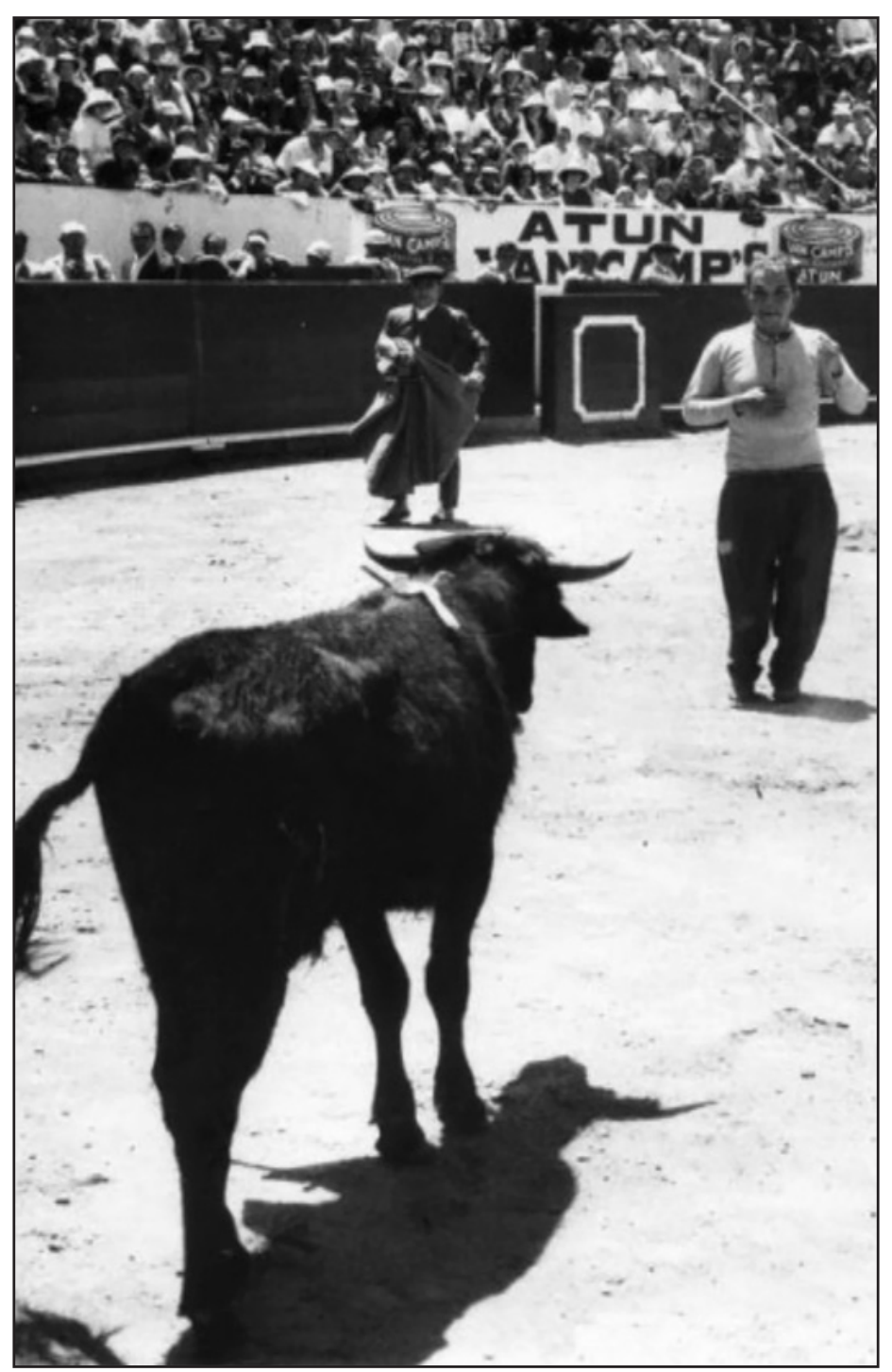

Figura 3. Festival artístico en la Plaza de Toros de Quito. Fuente: Quito Nostálgico.

La Monumental Plaza de Toros Quito fue construida en el barrio de Iñaquito, en el norte de la ciudad, en el año 1960, con una capacidad aproximada de 15.000 personas. En ella se organizó una de las ferias taurinas más importantes de América llamada Feria de Quito "Jesús del Gran Poder" realizada ininterrumpidamente hasta el año 2011, cuando la consulta popular decidió la prohibición de matar animales en espectáculos públicos en la ciudad, lo que derivó en una pérdida de expectativa y la empresa encargada de la organización, finalmente, suspendió el evento. La plaza también albergó importantes conciertos musicales y encuentros boxísticos que acaparaban gran interés de los quiteños.

El deporte más popular del mundo, el fútbol, cobraba fuerza a nivel mundial con la realización de la primera copa mundial celebrada en Uruguay en 1930; por lo cual Quito se hizo eco de ello y construyó el primer estadio frente al parque El Ejido, conocido como el Estadio del Arbolito, en donde se disputaron encuentros de fútbol profesional tanto a nivel provincial como nacional, el escenario se convirtió en el lugar favorito para los aficionados del deporte en la capital. El estadio El Arbolito fue perdiendo importancia luego de la inauguración del Estadio Olímpico Atahualpa en 1951, razón por lo cual fue demolido y se convertiría en el parque del Arbolito. El estadio Atahualpa sigue vigente hasta la actualidad y es el más reconocido del país debido a sus grandes gestas deportivas (Figura 5). 


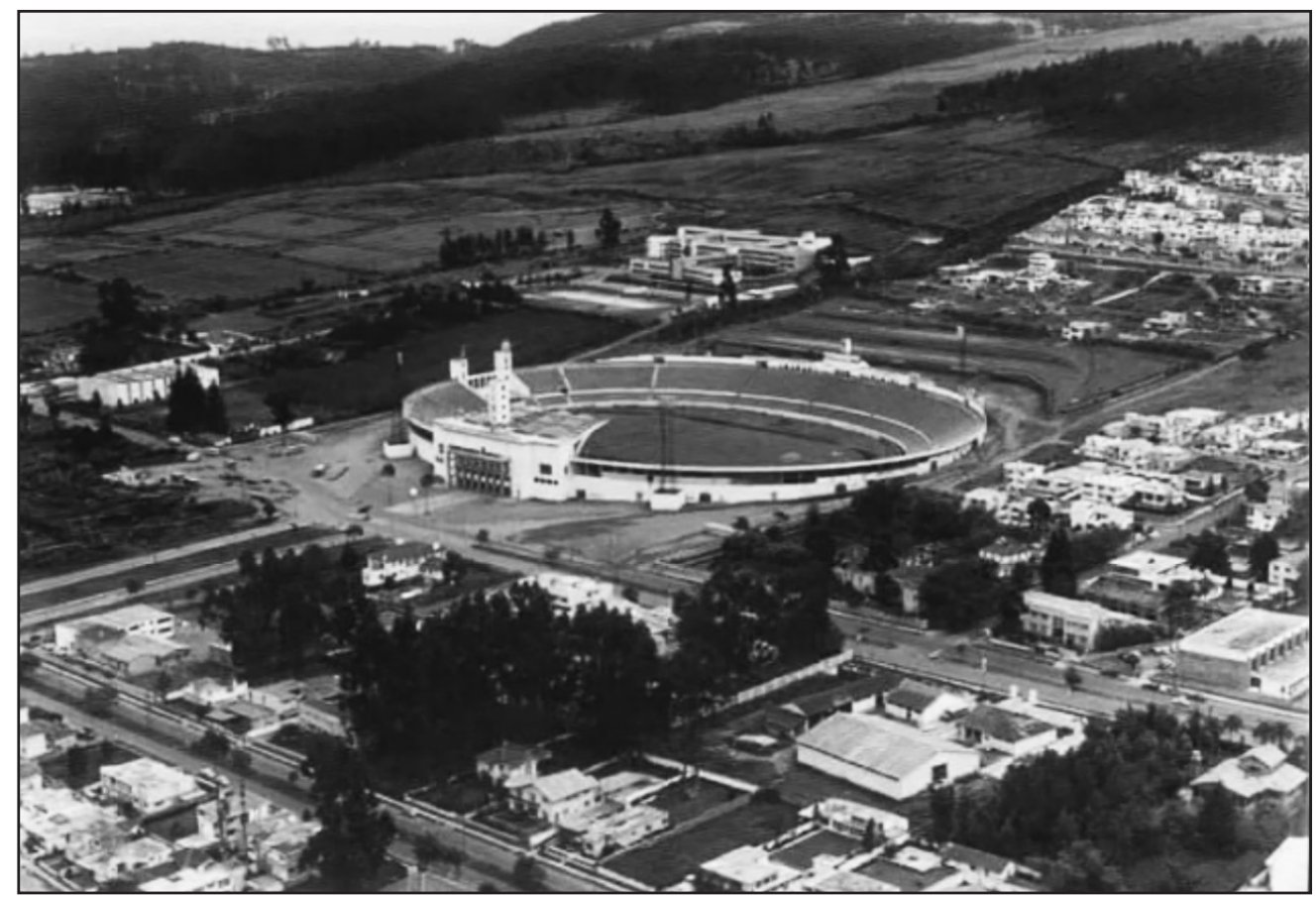

Figura 5. Estadio Olímpico Atahualpa. Fuente: Quito Nostálgico.

A partir de 1950, el deporte amateur empezó a tomar fuerza en los principales barrios de la ciudad dando énfasis a la disciplina del fútbol, pero recién se fortaleció institucionalmente en 1957, al fundarse la Federación de Ligas Deportivas Barriales y Parroquiales del Cantón Quito. Esta organización fue creciendo paulatinamente al ritmo de la ciudad. Las primeras ligas barriales en sumarse fueron las ligas La Tola, San Juan y Santa Prisca del centro; Central Obrera de Chimbacalle y La Magdalena en el sur; y, Chaupicruz en el norte. Actualmente son 100 ligas deportivas barriales en el cantón Quito. Cabe recalcar que hoy en día existen instituciones paralelas a la Federación de Ligas que concentran a otras ligas deportivas barriales tanto a nivel local como nacional.

\subsection{Propuesta de clasificación de los espacios públicos de ocio}

Paulatinamente, los espacios públicos de ocio se convirtieron en necesarios para el relax de los quiteños, y es así que todas las administraciones de turno facilitaron la creación y mejoramiento de las canchas, plazas y parques, entre otros equipamientos, en especial en los sectores norte y sur de la urbe, hacia donde se produce la expansión de la ciudad como producto del crecimiento poblacional, que se nutre de las constantes migraciones ocurridas desde otras provincias del Ecuador y también del aumento significativo de residentes extranjeros, destacándose las poblaciones procedentes de Cuba, Colombia y Perú.

A la par de este crecimiento poblacional, los espacios públicos de ocio incrementan su importancia y se han ido configurando de acuerdo con la realidad de la ciudad. El estudio realizado, permite presentar, a continuación, una clasificación propia, elaborada por los autores sobre los espacios públicos de ocio para la ciudad de Quito producto de la identificación, organización y sistematización de información sobre los lugares como alternativas de ocio en la urbe.

La elaboración de las categorías y subcategorías están realizadas con base en los servicios que prestan estos espacios a la población; los conceptos que a continuación se emiten son una muestra de la realidad del área de estudio seleccionada.

Dentro de la categoría recreacional se identifican al bosque protector, Casa Somos (en un comienzo conocido como Centro de desarrollo comunitario), mirador, parque arqueológico, parque lineal, parque metropolitano, parque urbano y plaza. 
Tabla 1. Clasificación de los espacios públicos de ocio en el área urbana de Quito

ESPACIOS PÚBLICOS DE OCIO EN LA CIUDAD DE QUITO

\begin{tabular}{|c|c|}
\hline \multicolumn{2}{|c|}{ Categorías } \\
\hline Espacio Recreativo & Espacio Deportivo \\
\hline Subcategoría & Subcategoría \\
\hline \multicolumn{2}{|l|}{ Bosque Protector } \\
\hline & Cancha \\
\hline \multicolumn{2}{|l|}{ Casa Somos } \\
\hline Mirador & Centro Deportivo \\
\hline Parque Arqueológico & Coliseo \\
\hline \multicolumn{2}{|l|}{ Parque Lineal } \\
\hline & Estadio \\
\hline \multicolumn{2}{|l|}{ Parque Metropolitano } \\
\hline \multicolumn{2}{|l|}{ Parque Urbano } \\
\hline & Liga Deportiva Barrial \\
\hline Plaza & \\
\hline
\end{tabular}

A continuación se presentan las definiciones de los espacios públicos dedicados a la recreación en la metrópoli.

- Bosque Protector.- La Ley Forestal (2004) vigente en el país, define en su artículo 6 al bosque y vegetación protectores como "aquellas formaciones vegetales, naturales o cultivadas, que cumplan con uno o más de los siguientes requisitos: Tener como función principal la conservación de suelo y la vida silvestre; estar situados en áreas que permitan controlar fenómenos pluviales torrenciales o la preservación de cuencas hidrográficas, especialmente en las zonas de escasa precipitación pluvial; ocupar cejas de montaña o áreas contiguas a las fuentes, corrientes o depósitos de agua; constituir cortinas rompevientos o de protección del equilibrio del medio ambiente; hallarse en áreas de investigación hidrológico-forestal; estar localizados en zonas estratégicas para la defensa nacional; y constituir factor de defensa de los recursos naturales y de obras de infraestructura de interés público".

- Casa Somos (Centro de Desarrollo Comunitario).- Es un lugar de encuentro para desarrollar habilidades artísticas, recreacionales y de emprendimiento, integrando a la comunidad a escala barrial. Está regido bajo la dirección de las administraciones zonales de Quito. En un inicio nació bajo el nombre de centro de desarrollo comunitario, pero la administración de turno concibió el cambio de nombre a Casa Somos.

- Mirador.- Es considerado como un sitio de observación del paisaje. Se encuentra ubicado en las partes altas con una amplia panorámica del entorno.

- Parque Arqueológico.- Complejo ancestral abierto al público, se complementa con las facilidades de visita de un área verde.

Parque Lineal.- Es un espacio longitudinal equipado con instalaciones para la recreación. Fue creado para el mejoramiento del ornato de las ciudades y la recuperación de ecosistemas urbanos.

Parque Metropolitano.- Es un gran espacio verde considerado como el pulmón de la ciu- 
dad, dedicado a la conservación y a la recreación. Este parque se encuentra administrado por el Municipio.

- Parque Urbano.- Espacio verde abierto diseñado en la trama urbana que provee servicios recreativos y sirve como sitio de referencia para conocer una ciudad.

- Plaza.- Espacio público ubicado en las zonas principales de la ciudad con gran importancia histórica-cultural. La plaza es un sitio de encuentro social construido con elementos culturales llamativos en conjunción con la naturaleza.

La oferta más llamativa en esparcimiento y recreación en la actualidad son los grandes parques metropolitanos, que se caracterizan por sus amplias áreas verdes, los múltiples servicios que cuentan y la diversidad de actividades que se pueden realizar en sus inmediaciones. Estos parques se localizan en las zonas periféricas y son de fácil acceso para los residentes y visitantes. El parque metropolitano más importante ubicado al norte de la ciudad es el Guangüiltagua con 557 ha, un sitio ideal para conocer la flora y fauna endémica de Quito. El Bicentenario, con 127 ha fue diseñado en las inmediaciones del antiguo aeropuerto Mariscal Sucre y está ubicado dentro de la zona norte, es un lugar que comparte la recreación con la concentración de servicios públicos municipales. Al sur de la ciudad están los parques: Las Cuadras (24 ha), Chilibulo (320 ha) y Metropolitano del Sur (750 ha), que se han convertido en zonas emblemáticas para los usuarios, debido a su importancia natural y a la recuperación de quebradas y laderas.

En el caso de los parques urbanos, el más representativo es La Carolina, un espacio público ubicado en la zona comercial de Quito, que ha ido evolucionando acorde al desarrollo de la urbe. Tiene una gran oferta recreacional, además de contar con servicios culturales, entre los que se destacan una feria de exposiciones, el Vivarium y el Museo de Ciencias Naturales.

Los parques como El Ejido y La Alameda, situados en el centro de la ciudad, son lo más tradicionales, y poseen un gran componente histórico, testigos de la rápida evolución de Quito.
Las plazas con gran valor histórico-cultural, se concentran en el centro antiguo de la urbe. Se destacan la Plaza Grande y la plaza de San Francisco. La primera, es un punto obligado de visita a la ciudad, un icono independentista con mucho valor para los ecuatorianos. Alrededor de la plaza se distribuyen los poderes ejecutivo, municipal y religioso de la localidad. Por su parte, la plaza de San Francisco, es una construcción colonial que cuenta con un hermoso paisaje urbano a los pies de la iglesia y con un convento de la orden religiosa franciscana.

El relieve irregular de Quito produjo que otros sitios de recreación sean los miradores, sitios altos que ofrecen panorámicas de diferentes partes del territorio, entre los cuales se destacan el Panecillo y el Itchimbía. El Panecillo es el más significativo, es una loma que cuenta en su parte superior con el monumento a la Virgen de Legarda o la Virgen de Quito. Al lugar concurren muchos turistas y residentes que obtienen una panorámica del centro y sur de la metrópoli, y cuenta con locales de venta de artesanías y restaurantes para disfrutar de la gastronomía nacional e internacional. El Itchimbía también es un parque urbano, y es posible observar una vista privilegiada de $360^{\circ}$. En sus inmediaciones cuenta con un centro cultural conocido como el palacio de cristal, y con frecuencia se realizan exposiciones, eventos culturales y conciertos.

En las laderas de las áreas occidental y oriental se han instaurado bosques protectores cuya finalidad es la conservación, y los residentes aprovechan la naturaleza para la práctica de actividades recreacionales, siendo las más habituales el atletismo y las caminatas por los senderos.

Los parques lineales han ayudado a recuperar las zonas aledañas a los ríos de la capital afectados por la contaminación. Actualmente, las zonas circundantes a los ríos son el escenario ideal para la práctica de actividades recreacionales, se destaca aquí el Parque Lineal Machángara con $21 \mathrm{~km}$ de extensión, que cuenta con iluminación y ayuda a luchar contra la inseguridad que afloraba permanentemente en estos sectores.

Existe un solo parque arqueológico conocido como Rumipamba. Se trata de una oferta turística y edu- 
cativa. El parque se caracteriza por ser un complejo arqueológico con vestigios precolombinos de la cultura de los yumbos, lo que le otorga un valor patrimonial alto, y cuenta, asimismo, con senderos ecológicos que facilitan las visitas.

La categoría espacio deportivo está integrada por: cancha, centro deportivo, coliseo, estadio y liga deportiva barrial a continuación sus definiciones.

- Cancha.- Área para la realización de uno o varios deportes. Puede estar al aire libre o en espacios cerrados.

- Centro Deportivo.- Es una construcción diseñada con todas facilidades para la práctica y la competición de varias disciplinas deportivas.

- Coliseo.- Edificación cerrada con graderíos, está concebida para la práctica y competición deportiva; además en ocasiones es un sitio dedicado a la presentación de eventos artísticos.

- $\quad$ Estadio.- Instalación deportiva de gran magnitud diseñada para la realización de importantes competencias a nivel local, nacional e internacional.

- Liga Deportiva Barrial.- Es una organización que fomenta la recreación y la práctica del deporte amateur en las instalaciones de sus entes afiliados. Cada liga barrial tiene su predio producto de donación o comodato municipal. En el caso del comodato es ejecutado máximo a 20 años renovables previo informe técnico emitido por la dirección de deportes de la respectiva administración zonal del municipio de Quito.

Si bien los espacios de recreación cuentan con sitios para la práctica deportiva, los espacios deportivos están configurados para la práctica competitiva, tanto a nivel profesional como amateur.

Los escenarios deportivos de gran magnitud en la ciudad son los estadios de fútbol, entre los cuales se destacan los estadios: Olímpico Atahualpa, Rodrigo Paz Delgado y Gonzalo Pozo Ripalda, que concentran importantes torneos a nivel nacional e internacional por su capacidad y oferta deportiva. Por otro lado, Quito cuenta con los coliseos Julio César
Hidalgo, Rumiñahui y Quitus, que acaparan la atención por la realización de varios eventos deportivos, entre los que llaman la atención el básquet, el ecuavóley, el boxeo, entre otros.

La Concentración Deportiva de Pichincha y el Ministerio del Deporte cuentan con equipamiento e instalaciones que permiten la preparación de deportistas para diferentes torneos provinciales, nacionales e internacionales en varias disciplinas: gimnasios, centros de natación, pistas de atletismo, velódromos y polideportivos. El uso no se restringe a la alta competición, sino que es posible utilizarlo en horarios ampliados para la población local.

A lo largo de la ciudad se encuentran múltiples canchas, en especial de deportes como el fútbol, indor fútbol, básquet y ecuavóley. De manera más organizada se encuentran las ligas deportivas barriales, que se caracterizan por aglutinar a los deportistas amateur en sus complejos. Las ligas barriales han ocupado históricamente espacios públicos que han sido cedidos en donación o comodato municipal, realizando gestión sobre sus inmediaciones y siendo atrayentes para el deporte a escala barrial. Una organización precursora es la Federación de Ligas Barriales y Deportivas del Cantón Quito que organiza anualmente múltiples eventos deportivos que integran un alto número de barrios y fomentan actividades atléticas entre niños, jóvenes, adultos y la tercera edad.

La Tabla 2 revela la gran cantidad de espacios de recreación disponibles en la ciudad. En su gran mayoría se encuentran en la categoría de parques urbanos, totalizando 143, además de nueve zonas recreacionales en los siete bosques protectores, 14 centros de desarrollo comunitario, 13 miradores, 22 plazas, tres parques lineales, cinco parques metropolitanos y un espacio con una denominación especial de parque arqueológico. En total suman 210 espacios dedicados a la recreación.

La importancia deportiva a escala barrial es de relevancia en la urbe, la Tabla 3 ayuda a visualizar los lugares donde se practica el deporte de forma cotidiana, en su gran mayoría se encuentran los 105 espacios de las ligas deportivas barriales, en menor proporción, pero a la vez vital para esta categoría, están las 20 canchas, 10 centros deportivos, 3 coliseos y 4 estadios. 
Tabla 2. Los principales espacios recreativos de la ciudad de Quito con su clasificación en la categoría "espacio recreativo".

\begin{tabular}{|c|c|}
\hline $\mathbf{N}^{\mathbf{o}}$ & Nombre \\
\hline \multicolumn{2}{|r|}{ Subcategoría: Bosque Protector } \\
\hline 1 & Bosque Protegido El Bosque \\
\hline 2 & Bosque Protegido Iñaquito Alto \\
\hline 3 & Bosque Protegido San Juan \\
\hline 4 & Bosque Protegido Cochapamba Alta \\
\hline 5 & Bosque Protegido La Florida \\
\hline 6 & Bosque Protegido San Carlos \\
\hline 7 & Bosque Protegido Puengasí Zona 1 \\
\hline 8 & Bosque Protegido de Puengasí Zona 2 \\
\hline 9 & Bosque Protegido de Puengasí Zona 3 \\
\hline \multicolumn{2}{|r|}{ Subcategoría: Casa Somos } \\
\hline 10 & Casa Somos La Tola \\
\hline 11 & Casa Somos Toctiuco \\
\hline 12 & Casa Somos Guamaní \\
\hline 13 & Casa Somos San Marcos \\
\hline 14 & Casa Somos San Diego \\
\hline 15 & Casa Somos Atahualpa \\
\hline
\end{tabular}

\begin{tabular}{|c|c|}
\hline $\mathbf{N}^{0}$ & Nombre \\
\hline \multicolumn{2}{|r|}{ Subcategoría: Parque Urbano } \\
\hline 103 & Parque Jipijapa \\
\hline 104 & Louvre Park \\
\hline 105 & Parque Pedro Jorge Vera \\
\hline 106 & Parque República Dominicana \\
\hline 107 & Redondel de la Floresta \\
\hline 108 & Parque Pío XII \\
\hline 109 & Parque Italia \\
\hline 110 & Parque de Santa Clara de San Millán \\
\hline 111 & Parque de la UTE \\
\hline 112 & Parques de los Manzanos \\
\hline 113 & Parque el Jardín de las Damas \\
\hline 114 & Parque Nueva Aurora \\
\hline 115 & Parque Solidaridad \\
\hline 116 & Parque Bretaña \\
\hline 117 & Parque Sixto María Durán \\
\hline 118 & Parque de la Concepción \\
\hline
\end{tabular}




\begin{tabular}{|c|c|}
\hline 16 & Casa Somos Chilibulo \\
\hline 17 & Casa Somos La Ferroviaria \\
\hline 18 & Casa Somos La Roldós \\
\hline 19 & Casa Somos Monjas \\
\hline 20 & Casa Somos Chillogallo \\
\hline 21 & Casa Somos Cotocollao \\
\hline 22 & Casa Somos Carcelén Bajo \\
\hline 23 & Casa Somos La Tola 2 \\
\hline & Subcategoría: Mirador \\
\hline 24 & Mirador del Panecillo \\
\hline 25 & Mirador Cima de La Libertad \\
\hline 26 & Mirador del Pichincha \\
\hline 27 & Mirador de Cruz Loma \\
\hline 28 & Miravalle \\
\hline 29 & Mirador de Puengasí \\
\hline 30 & Mirador Yaku-Museo del Agua \\
\hline 31 & Mirador de Toctiuco \\
\hline 32 & Mirador del Itchimbía \\
\hline 33 & $\begin{array}{l}\text { Mirador del Parque Metropolitano Guan- } \\
\text { güiltagua }\end{array}$ \\
\hline 34 & Mirador de Guápulo \\
\hline
\end{tabular}

\begin{tabular}{|c|c|}
\hline 119 & Parque Diego de Tapia \\
\hline 120 & Parque Einstein \\
\hline 121 & Parque La Luz \\
\hline 122 & Parque Sebastián de Benalcázar \\
\hline 123 & Parque El Sena \\
\hline 124 & Parque del Museo Interactivo de Ciencias \\
\hline 125 & Parque Fulton \\
\hline 126 & Parque Conchas Azules \\
\hline 127 & Parque Spencer \\
\hline 128 & Parque Cacique Píntag \\
\hline 129 & Parque El Pintado \\
\hline 130 & Parque Ponceano \\
\hline 131 & Parque Entrada Carapungo \\
\hline 132 & Parque Primavera \\
\hline 133 & Parque Pinar Alto \\
\hline 134 & Parque Equinoccial \\
\hline 135 & Parque del Conjunto El Jardín \\
\hline 136 & Parque de San Pedro Claver 1 \\
\hline 137 & Parque San Pedro Claver 2 \\
\hline 138 & Parque San Pedro Claver \\
\hline
\end{tabular}




\begin{tabular}{|c|c|}
\hline 35 & Mirador de San Juan \\
\hline 36 & Mirador de los Pobres \\
\hline \multicolumn{2}{|r|}{ Subcategoría: Parque Arqueológico } \\
\hline 37 & $\begin{array}{l}\text { Parque Arqueológico y Ecológico Rumi- } \\
\text { pamba }\end{array}$ \\
\hline \multicolumn{2}{|r|}{ Subcategoría: Parque Lineal } \\
\hline 38 & Parque Lineal Machángara \\
\hline 39 & Parque Lineal Río Grande \\
\hline 40 & Parque Lineal Cardenal de la Torre \\
\hline \multicolumn{2}{|r|}{ Subcategoría: Parque Metropolitano } \\
\hline 41 & Parque Metropolitano Guangüiltagua \\
\hline 42 & Parque Metropolitano del Sur \\
\hline 43 & Parque Metropolitano de La Armenia \\
\hline 44 & Parque Metropolitano Cuscungo \\
\hline 45 & $\begin{array}{l}\text { Parque Metropolitano Chilibulo Huayra- } \\
\text { pungo }\end{array}$ \\
\hline \multicolumn{2}{|r|}{ Subcategoría: Parque Urbano } \\
\hline 46 & Parque El Ejido \\
\hline 47 & Parque La Moya \\
\hline 48 & Parque La Carolina \\
\hline 49 & Parque del Itchimbía \\
\hline 50 & Parque Inglés \\
\hline
\end{tabular}

\begin{tabular}{|c|c|}
\hline 139 & Parque y canchas La Tola Alta \\
\hline 140 & Parque de La Tola \\
\hline 141 & Parque España \\
\hline 142 & Parque Unión Nacional \\
\hline 143 & Parque Circasiana \\
\hline 144 & Parque Quebrada Ortega \\
\hline 145 & Parque de Chilibulo \\
\hline 146 & Parque El Calzado \\
\hline 147 & Parque 17 de Julio/La Ferroviaria \\
\hline 148 & Parque El Pobre Diablo \\
\hline 149 & Parque del Gallo \\
\hline 150 & Parque Ciudadela El Comercio \\
\hline 151 & Parque La Alameda \\
\hline 152 & Parque Los Laureles \\
\hline 153 & Parque Infantil \\
\hline 154 & Parque Mariana de Jesús \\
\hline 155 & Parque José María Escrivá de Balaguer \\
\hline 156 & Parque Mayor Galo Molina \\
\hline 157 & Parque Pisulí \\
\hline 158 & Parque de Carcelén Bajo \\
\hline
\end{tabular}




\begin{tabular}{|c|c|}
\hline 51 & Parque Andalucía \\
\hline 52 & Parque Plaza América \\
\hline 53 & Parque La Isla \\
\hline 54 & Parque La Libertad \\
\hline 55 & Parque Santa Ana 1 \\
\hline 56 & Parque La Recoleta \\
\hline 57 & Parque Ecológico Santa Ana \\
\hline 58 & Parque Ciudadela Santiago \\
\hline 59 & Parque Ecológico Chilibulo \\
\hline 60 & Fundeporte \\
\hline 61 & Parque de La Mujer y El Niño \\
\hline 62 & Parque del Arbolito \\
\hline 63 & Parque Julio Matovelle \\
\hline 64 & Parque Julio Andrade Marín \\
\hline 65 & Parque Gabriela Mistral \\
\hline 66 & Parque la Vicentina (El Relleno) \\
\hline 67 & Parque La Tolita \\
\hline 68 & Parque García Moreno \\
\hline 69 & Parque Las Cuadras \\
\hline 70 & Parque Campo Matovelle \\
\hline
\end{tabular}

\begin{tabular}{|c|c|}
\hline 159 & Parque Pampite \\
\hline 160 & Parque California Bonanza \\
\hline 161 & Parque Cofavi \\
\hline 162 & Parque de la Canela \\
\hline 163 & Parque Ex Combatientes del 41 \\
\hline 164 & Parque Cooperativa 14 de Enero \\
\hline 165 & Parque Amigo \\
\hline 166 & Parque Eduardo Borja Pérez \\
\hline 167 & Parque Germán Ávila Saá \\
\hline 168 & Parque de la E \\
\hline 169 & Parque El Carmen \\
\hline 170 & $\begin{array}{l}\text { Parque Teniente Hugo Ortiz-Diego Mejía y Juan de } \\
\text { Alcántara }\end{array}$ \\
\hline 171 & Parque Caupicho \\
\hline 172 & Parque San José de Guamaní \\
\hline 173 & Parque San Martín de Porres \\
\hline 174 & Parque La Bota \\
\hline 175 & Parque Nuestra Señora de El Cisne \\
\hline 176 & Parque Rumihurco \\
\hline 177 & Parque San José de Jarrín \\
\hline 178 & Parque Thomas \\
\hline
\end{tabular}




\begin{tabular}{|c|c|}
\hline 71 & Parque Bicentenario \\
\hline 72 & Parque Ecológico Puertas del Sol \\
\hline 73 & Parque Matovelle \\
\hline 74 & Parque Lomas de Monteserrín \\
\hline 75 & Parque Escalina \\
\hline 76 & Parque Primicias \\
\hline 77 & Parque Ecológico Solanda \\
\hline 78 & Parque Ciudadela El Comercio \\
\hline 79 & Parque Japón \\
\hline 80 & Parque Suecia \\
\hline 81 & Parque Azkúnaga \\
\hline 82 & Parque Heraldo \\
\hline 83 & Parque Deportivo \\
\hline 84 & Parque República de Nicaragua \\
\hline 85 & Parque de La Mujer y Niño del Sur \\
\hline 86 & Parque Palmar \\
\hline 87 & Parque Chino \\
\hline 88 & Parque Pío Valdivieso \\
\hline 89 & Parque de la Kennedy \\
\hline
\end{tabular}

\begin{tabular}{|c|c|}
\hline 179 & Parque Las Casas \\
\hline 180 & Parque de Las Casas \\
\hline 181 & Parque Pambachupa \\
\hline 182 & Parque de La Altamira \\
\hline 183 & Parque Granda Centeno \\
\hline 184 & Parque El Bosque \\
\hline 185 & Parque España \\
\hline 186 & Parque Tiwinza \\
\hline & Subcategoría: Plaza \\
\hline 187 & Plaza de la Independencia \\
\hline 188 & Parque de los Enamorados \\
\hline 189 & Plaza Quitumbe \\
\hline 190 & Plaza República de Chile \\
\hline 191 & Parque La Magdalena \\
\hline 192 & Plaza de la República \\
\hline 193 & Plaza Argentina \\
\hline 194 & Parque Central de Chillogallo \\
\hline 195 & Parque Central de Perruno \\
\hline 196 & Plaza de Santo Domingo \\
\hline
\end{tabular}




\begin{tabular}{|l|l|}
\hline 90 & Parque Pío Jaramillo Alvarado \\
\hline 91 & Parque California \\
\hline 92 & Parque Tufino \\
\hline 93 & Parque Venecia \\
\hline 94 & Parque Guayaquil \\
\hline 95 & Parque Sodiro \\
\hline 96 & Parque Cumandá \\
\hline 101 & Parque Amazonas \\
\hline 92 & Parque Hugo Borja \\
\hline 90 & Parque Concha Acústica \\
\hline 90 Cumandá
\end{tabular}

\begin{tabular}{|l|l|}
\hline 197 & Plaza del Teatro \\
\hline 198 & Plaza Simón Bolívar \\
\hline 199 & Plaza Nicaragua \\
\hline 200 & Plaza República de Perú \\
\hline 201 & Plaza Costa Rica \\
\hline 202 & Plaza Cívica Eloy Alfaro \\
\hline 203 & Parque del Agua \\
\hline 204 & Plaza Victoria \\
\hline 205 & Plaza El Consuelo \\
\hline 207 & Plaza San Francisco \\
\hline
\end{tabular}

Tabla 3. Los principales espacios deportivos de la ciudad de Quito con su clasificación en la categoría "espacio deportivo"

\begin{tabular}{|l|l|}
\hline \multicolumn{2}{|c|}{ Nombre } \\
\hline \multicolumn{2}{|c|}{ Subcategoría: Canchas } \\
\hline 1 & Canchas Deportivo Quito \\
\hline 2 & Cancha y Tribuna del Sur \\
\hline 3 & Cancha Concha Acústica \\
\hline
\end{tabular}

\begin{tabular}{|l|l|}
\hline $\mathbf{N}^{\mathbf{0}}$ & \multicolumn{1}{|c|}{ Nombre } \\
\hline \multicolumn{2}{|c|}{ Subcategoría: Liga Deportiva Barrial } \\
\hline 70 & Liga Media Luna \\
\hline 71 & Liga Cotocollao \\
\hline 72 & $\begin{array}{l}\text { Federación de Ligas Barriales del Can- } \\
\text { tón Quito }\end{array}$ \\
\hline
\end{tabular}




\begin{tabular}{|c|c|}
\hline 4 & Cancha de indor 6 de Agosto \\
\hline 5 & Canchas Las Cuadras \\
\hline 6 & Pista Atlética Los Chasquis \\
\hline 7 & Velóromo José Luis Recalde \\
\hline 8 & Patinódromo Pichincha \\
\hline 9 & Club de golf de la FAE \\
\hline 10 & Cancha Altos de La Ferroviaria \\
\hline 11 & Cancha de básquet San José de Monjas \\
\hline 12 & Cancha Barrio Santa Ana Alta \\
\hline 13 & Canchas de ecuavóley y fútbol Chimbacalle \\
\hline 14 & Canchas de Pelota Nacional La Mena 2 \\
\hline 15 & Canchas Deportivas Primera Etapa Carapungo \\
\hline 16 & Canchas de la Clemente Ballén \\
\hline 17 & Canchas Múltiples de la Zona 8 \\
\hline 18 & Canchas de uso Múltiple vía a La Bota \\
\hline 19 & Cancha de uso múltiple Puruhanta \\
\hline 20 & Canchas de Santa Clara de Millán \\
\hline 21 & Complejo Deportivo Señor de los Milagros \\
\hline & Subcategoría: Centro Deportivo \\
\hline 22 & $\begin{array}{l}\text { Centro Deportivo Norte Concentración Deportiva de Pi- } \\
\text { chincha }\end{array}$ \\
\hline
\end{tabular}

\begin{tabular}{|c|c|}
\hline 73 & Liga El Condado \\
\hline 74 & Liga Guápulo \\
\hline 75 & Liga Bolivariana \\
\hline 76 & Liga El Inca \\
\hline 77 & Liga Itchimbía \\
\hline 78 & Liga John F. Kennedy \\
\hline 79 & Liga La Comuna \\
\hline 80 & Liga La Floresta \\
\hline 81 & Liga La Concordia \\
\hline 82 & Liga Ciudadela Ibarra \\
\hline 83 & Liga La Libertad de Chillogallo \\
\hline 84 & Liga Las Casas \\
\hline 85 & Liga Los Libertadores \\
\hline 86 & Liga Municipal \\
\hline 87 & Liga Oriental \\
\hline 88 & Liga San Isidro del Inca \\
\hline 89 & Liga San Juan \\
\hline 90 & Liga Toctiuco \\
\hline 91 & Liga Simón Bolívar \\
\hline 92 & Liga Solanda \\
\hline
\end{tabular}




\begin{tabular}{|c|c|}
\hline 23 & Centro Deportivo Metropolitano \\
\hline 24 & Centro Deportivo Ministerio del Deporte \\
\hline 25 & Gimnasio de Boxeo La Tola \\
\hline 26 & Gimnasio de Boxeo Chimbacalle \\
\hline 27 & $\begin{array}{l}\text { Centro Deportivo principal de la Concentración Deportiva } \\
\text { de Pichincha }\end{array}$ \\
\hline 28 & $\begin{array}{l}\text { Centro Deportivo de Natación Concentración Deportiva de } \\
\text { Pichincha }\end{array}$ \\
\hline 29 & Centro Deportivo César Alfonso Poli CDP \\
\hline 30 & Centro Deportivo Ministerio de Deportes \\
\hline 31 & Centro Deportivo CDP Cochapata \\
\hline & Subcategoría: Coliseo \\
\hline 32 & Coliseo Julio César Hidalgo \\
\hline 33 & Coliseo General Rumiñahui \\
\hline 34 & Coliseo Los Quitus \\
\hline 35 & Estadio Rodrigo Paz Delgado \\
\hline 36 & Estadio Universidad Central \\
\hline 37 & Estadio Olímpico Atahualpa \\
\hline 38 & Estadio Gonzalo Pozo Ripalda \\
\hline & Subcategoría: Liga Deportiva \\
\hline
\end{tabular}

\begin{tabular}{|c|c|}
\hline 93 & Liga San Sebastián \\
\hline 94 & Liga Unión de Ciudadelas \\
\hline 95 & Liga Unión Deportiva Eloy Alfaro \\
\hline 96 & Liga Andalucía \\
\hline 97 & Liga Chimborazo \\
\hline 98 & Liga Santa Clara de San Millán \\
\hline 99 & Liga Atucucho \\
\hline 100 & Liga Germán Ávila Saá \\
\hline 101 & Liga El Rosal \\
\hline 102 & Liga Cochapamba Sur \\
\hline 103 & Liga Cochapamba Norte \\
\hline 104 & Liga Bellavista \\
\hline 105 & Liga Carapungo \\
\hline 106 & Liga Carapungo Cancha 3 \\
\hline 107 & Liga Carcelén \\
\hline 108 & Liga La Bretaña \\
\hline 109 & Liga General Miller \\
\hline 110 & Liga Manuela Sáenz \\
\hline 111 & Liga Salvador Celi \\
\hline
\end{tabular}




\begin{tabular}{|c|c|c|c|}
\hline 39 & Liga Iñaquito & 112 & Liga Santa Rosa de La Argelia \\
\hline 40 & Liga Monteserrín & 113 & Liga Área Ecológica \\
\hline 41 & Liga Santa Ana de Chillogallo & 114 & Liga Súper Manzana H \\
\hline 42 & Liga El Salvador & 115 & Liga Andrús Kim \\
\hline 43 & Liga El Tránsito & 116 & Liga El Carmen \\
\hline 44 & Liga IESS-FUT & 117 & Liga Clemente Ballén \\
\hline 45 & Liga Chimbacalle & 118 & Liga de Turubamba de Monja \\
\hline 46 & Liga Félix Barreiro & 119 & Liga El Rocío \\
\hline 47 & Liga Chillogallo & 120 & Liga La Esperanza \\
\hline 48 & Liga Mariscal de Ayacucho & 121 & Liga Héroes de Paquisha \\
\hline 49 & Liga Quito Sur & 122 & Liga Martha Bucaram \\
\hline 50 & Liga Barrionuevo & 123 & Liga La Independencia \\
\hline 51 & Liga El Calzado & 124 & Liga 4 de Agosto \\
\hline 52 & Liga Santa Rita & 125 & Liga Primicias de Quito \\
\hline 53 & Liga Quiteño Libre & 126 & Liga Matilde Álvarez \\
\hline 54 & Liga Oriental (La Batea) & 127 & Liga San José de Guamaní \\
\hline 55 & Liga Chaupicruz & 128 & Liga Valle del Sur \\
\hline 56 & Liga La Vicentina & 129 & Liga Pueblo Unido \\
\hline 57 & Liga González Suárez & 130 & Liga San Luis \\
\hline 58 & Liga Santa Anita II & 131 & Liga Girón \\
\hline
\end{tabular}




\begin{tabular}{|l|l|}
\hline 59 & Liga La Magdalena \\
\hline 60 & Liga La Libertad \\
\hline 61 & Liga San Bartolo \\
\hline 62 & Liga Las Arcadias \\
\hline 63 & Liga San Roque \\
\hline 64 & Liga San José de Monjas \\
\hline 65 & Liga Pisulí \\
\hline 66 & Liga La Tola \\
\hline 67 & Liga Biloxi \\
\hline
\end{tabular}

\section{Conclusiones}

Los actuales espacios públicos de ocio son el reflejo de las inversiones de los gobiernos seccionales que intentan responder a las exigencias y al empoderamiento por parte de la sociedad civil. Como resultado, se observa que se ha logrado consolidar una significativa oferta de diversos lugares vinculada a las actividades recreativas, en especial las deportivas. En este marco, la clasificación propuesta responde a la construcción histórica de estos espacios. Las categorías y subcategorías establecidas se corresponden con la actual oferta que privilegia las actividades recreativas con especial énfasis en la competencia deportiva.

\section{Referencias}

Achig, L. (1983). El proceso urbano de Quito: ensayo de interpretación. Quito, Ecuador: CAE / Centro de Inv. Ciudad.

\begin{tabular}{|l|l|}
\hline 132 & Liga Santa Rosa \\
\hline 133 & Liga Jipijapa \\
\hline 134 & Liga Wilson Monge \\
\hline 135 & Liga Luchador Eloy Alfaro \\
\hline 136 & Liga Comité del Pueblo \\
\hline 137 & Liga La Florida \\
\hline 138 & Liga Caminos a la Libertad \\
\hline 139 & Liga San José de Cangahua \\
\hline 140 & Liga Consejo Provincial \\
\hline
\end{tabular}

La distribución de los espacios públicos con finalidad de ocio en Quito es desigual, debido a la topografía irregular de la ciudad y a la necesidad de conservación del patrimonio cultural del centro histórico (Anexos 1-5). La convivencia con el desarrollo de nuevas edificaciones resulta una preocupación constante de los administradores por las dificultades de accesibilidad a estos espacios.

La investigación propuesta resulta un primer paso en la comprensión de una temática actual que entrelaza la disponibilidad de tiempo libre y su relación con la producción de espacios con finalidad de ocio.
Carrión, A., Goetschel, A., y Sánchez, N. (1997). Breve historia de los servicios en la ciudad de Quito. Quito, Ecuador: Ciudad. 
Dumazedier, J., Kaes, R., Mageyt, M. et al. (1971). Ocio y sociedad de las clases. Barcelona, España: Fontanella .

Fleury, A, (2007). Les espaces publics dans les politiques métropolitaines. Réflexions au croisement de trois expériences. De Paris aux quartiers centraux de Berlin et Istanbul, (Thèse de doctorat en géographie), Université Panthéon - Sorbonne Paris I, Paris, Francia.

Ley Forestal y de Conservación. (2004). Áreas naturales y vida silvestre. Quito, Ecuador: Corporación de Estudios y Publicaciones, primera edición.
Narváez, N. (24 de agosto de 1982). El balneario de "Los Pogyos" un recuerdo de los quiteños. Diario El Comercio

Ortiz, A. (18 de mayo 2014). Los especiales. Diario El Comercio. Recuperado http://especiales.elcomercio.com/planeta-ideas/ideas/18mayo-2014/adalberto-ortiz-literatura

Ulloa, S., \& Darquea, G. (1983). Estudio del desarrollo histórico de Quito. Quito, Ecuador: CAE / Centro de Inv. Ciudad.

Varela, S. (1999). Espacio privado, espacio público: dialécticas urbanas y construcción de significados. Tres al Cuarto, 6, 22-24.

Anexo 1. Localización de los espacios públicos de ocio de Quito en el sector denominado Norte
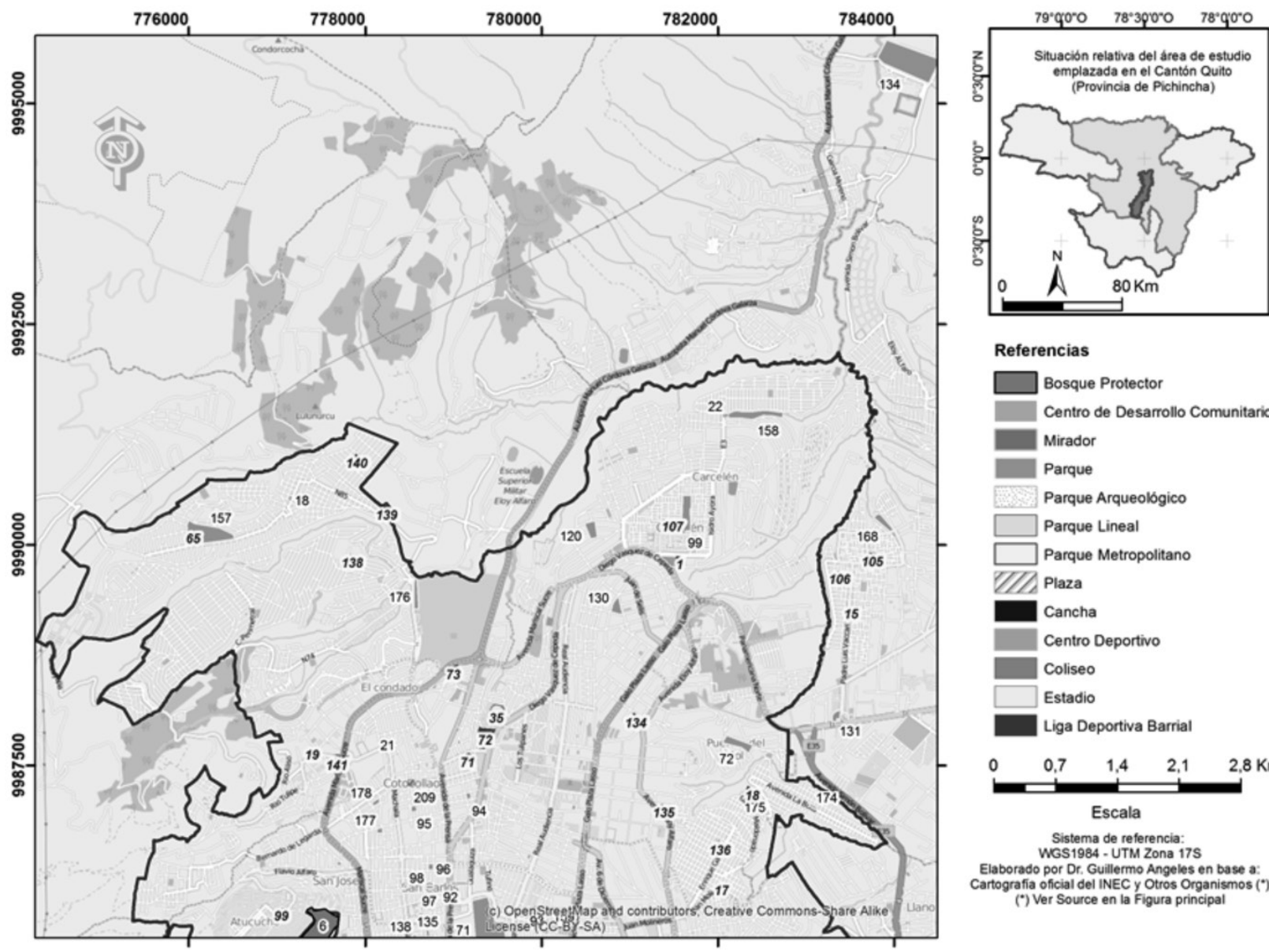

Referencias

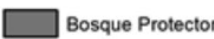

Centro de Desarrollo Comunitario

Mirador

Parque

Parque Arqueologico

Parque Lineal

Parque Metropolitano

DIA Plaza

Cancha

Centro Deportivo

Coliseo

Estadio

Liga Deportiva Barrial

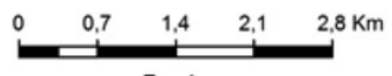

Escala

Sistema de referencia:

rado por Dr. Guillermo Angeles en base a: (i) Vis (") Ver Source en la Figura principa 
Anexo 2. Localización de los espacios públicos de ocio de Quito en el sector denominado Centro Norte.

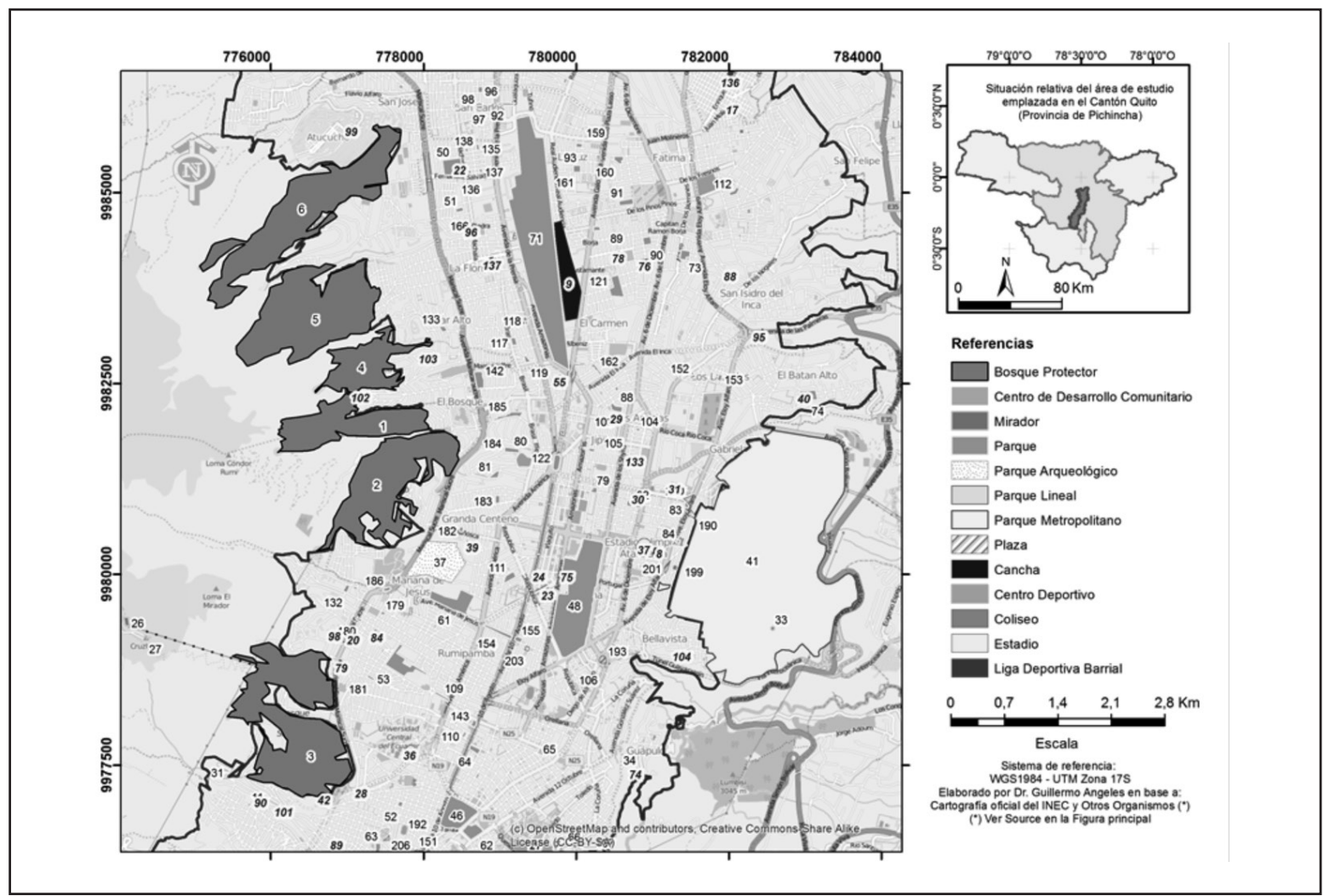

Anexo 3. Localización de los espacios públicos de ocio de Quito en el sector denominado Centro.

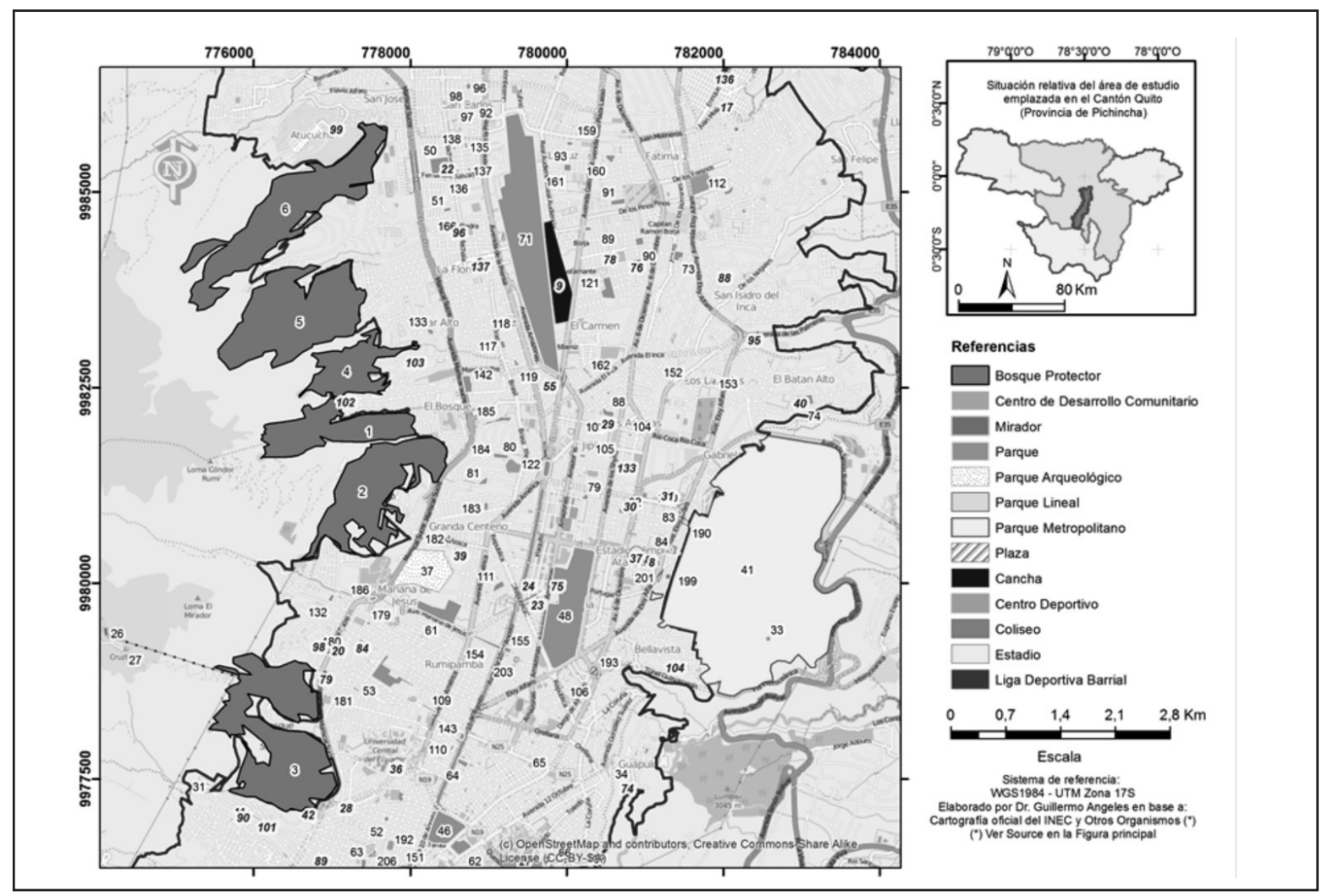


Anexo 4. Localización de los espacios públicos de ocio de Quito en el sector denominado Centro-Sur.

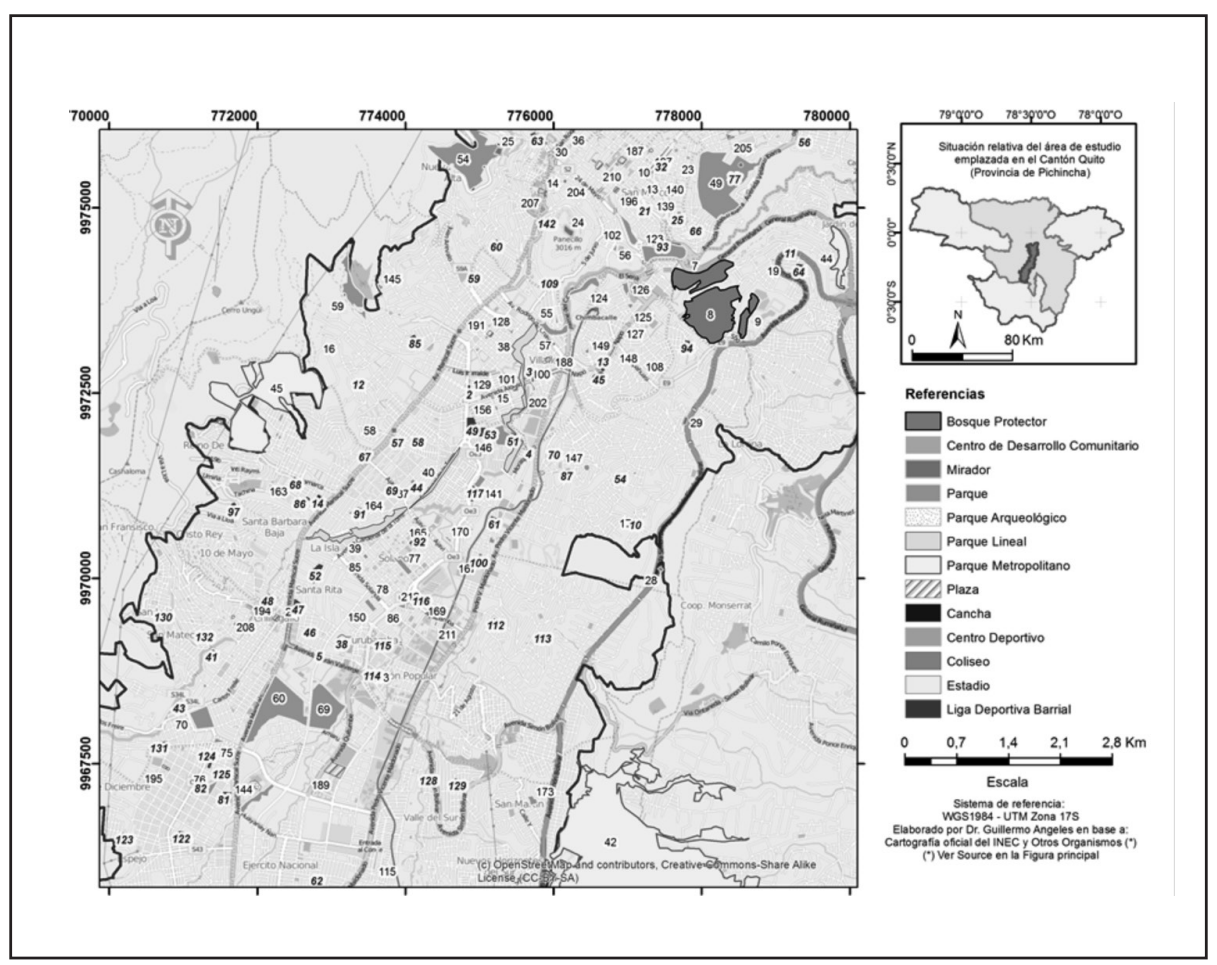

Anexo 5. Localización de los espacios públicos de ocio de Quito en el sector denominado Sur.

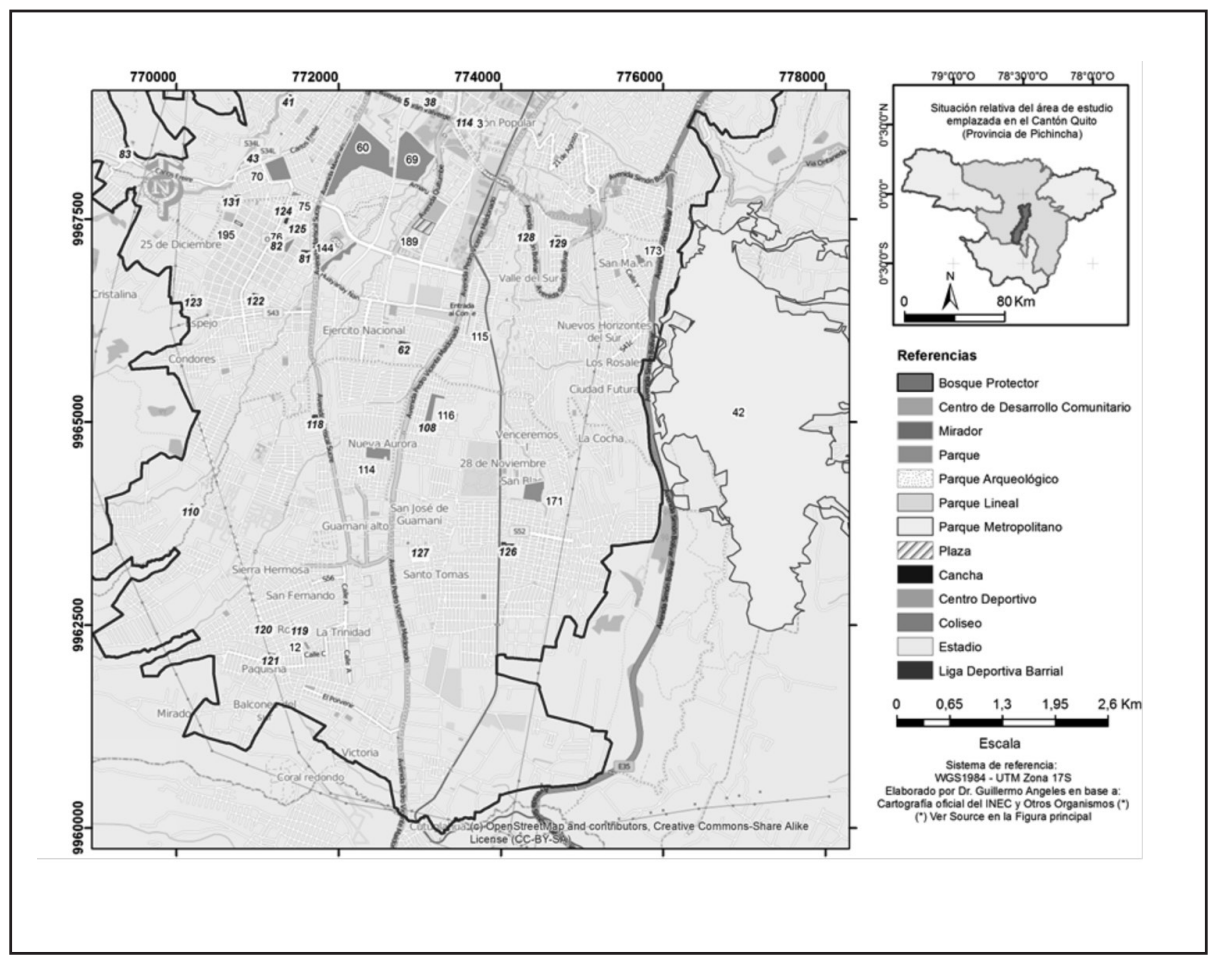

